\title{
Gas Gun Model and Comparison to Experimental Performance of Pipe Guns Operating with Light Propellant Gases and Large Cryogenic Pellets*
}

\author{
S. K. Combs ${ }^{1}$, J. R. Reed ${ }^{2}$, M. S. Lyttle ${ }^{1}$, L. R. Baylor ${ }^{1}$, J. R. Carmichael ${ }^{3}$, T. E. Gebhart ${ }^{4}$, \\ S. J. Meitner ${ }^{1}$, and D. A. Rasmussen ${ }^{1}$ \\ ${ }^{1}$ Oak Ridge National Laboratory, Oak Ridge, Tennessee, USA \\ ${ }^{2}$ University of Tennessee, Knoxville, Tennessee, USA \\ ${ }^{3}$ Fermi National Accelerator Laboratory, Batavia, Illinois, USA \\ ${ }^{4}$ University of Florida, Gainesville, Florida, USA
}

\author{
Corresponding author: $\quad$ Stephen K. Combs \\ Oak Ridge National Laboratory \\ P. O. Box 2008 \\ Oak Ridge, TN 37831-6169 \\ Email: combssk@ornl.gov
}

Fax: 865-576-7926

Phone: 865-574-9985 (Cell: 865-803-6839)

Total number of pages: 29

Number of tables: 1

Number of figures: 11

\begin{abstract}
*This manuscript has been authored by UT-Battelle, LLC under Contract No. DE-AC0500OR22725 with the U.S. Department of Energy. The United States Government retains and the publisher, by accepting the article for publication, acknowledges that the United States Government retains a non-exclusive, paid-up, irrevocable, worldwide license to publish or reproduce the published form of this manuscript, or allow others to do so, for United States Government purposes. The Department of Energy will provide public access to these results of federally sponsored research in accordance with the DOE Public Access Plan (http://energy.gov/downloads/doe-public-access-plan). The views and opinions expressed herein do not necessarily reflect those of the ITER Organization.
\end{abstract}


Abstract - Injection of multiple large ( $\sim 10$ to $30 \mathrm{~mm}$ diameter) shattered pellets into ITER plasmas is presently part of the scheme planned to mitigate the deleterious effects of disruptions on the vessel components. To help in the design and optimize performance of the pellet injectors for this application, a model referred to as "the gas gun simulator" has been developed and benchmarked against experimental data. The computer code simulator is a Java program that models the gas-dynamics characteristics of a single-stage gas gun. Following a stepwise approach, the code utilizes a variety of input parameters to incrementally simulate and analyze the dynamics of the gun as the projectile is launched down the barrel. Using input data, the model can calculate gun performance based on physical characteristics, such as propellant-gas and fast-valve properties, barrel geometry, and pellet mass. Although the model is fundamentally generic, the present version is configured to accommodate cryogenic pellets composed of $\mathrm{H}_{2}, \mathrm{D}_{2}$, $\mathrm{Ne}$, Ar, and mixtures of them and light propellant gases $\left(\mathrm{H}_{2}, \mathrm{D}_{2}\right.$, and $\left.\mathrm{He}\right)$. The pellets are solidified in situ in pipe guns that consist of stainless steel tubes and fast-acting valves that provide the propellant gas for pellet acceleration (to speeds $\sim 200$ to $700 \mathrm{~m} / \mathrm{s}$ ). The pellet speed is the key parameter in determining the response time of a shattered pellet system to a plasma disruption event. The calculated speeds from the code simulations of experiments were typically in excellent agreement with the measured values. With the gas gun simulator validated for many test shots and over a wide range of physical and operating parameters, it is a valuable tool for optimization of the injector design, including the fast valve design (orifice size and volume) for any operating pressure ( 40 bar expected for the ITER application) and barrel length for any pellet size (mass, diameter, and length). Key design parameters and proposed values for the pellet injectors for the ITER disruption mitigation systems are discussed.

Keywords - Gas gun model, plasma disruption mitigation, shattered cryogenic pellet, ITER 


\section{INTRODUCTION}

For several decades, gas guns have commonly been used to accelerate cryogenic pellets for injection into experimental fusion plasmas. ${ }^{1-3}$ Light gases $\left(\mathrm{H}_{2}, \mathrm{D}_{2}\right.$, or $\left.\mathrm{He}\right)$ are the preferred propellant because their high sound speeds ( $\sim 900$ to $1300 \mathrm{~m} / \mathrm{s}$ at room temperature) will yield maximum acceleration. The pellets are formed by solidification of gases at temperatures below the corresponding triple points. Isotopes of hydrogen $\left(\mathrm{H}_{2}\right.$ and $\left.\mathrm{D}_{2}\right)$ have been the material used most often for cryogenic pellets, with the principal objective of depositing atoms of fuel deeper into the plasma core. Even operations with $\mathrm{T}_{2}$ and D-T (deuterium-tritium) mixtures have been achieved by Fisher et. al. ${ }^{4,5}$ in a specialized facility. In addition to the hydrogen isotopes, pellets composed of $\mathrm{Ne}$ or Ar have sometimes been utilized in plasma experiments for impurity and particle transport studies. The pellet sizes used in fusion experiments around the world have generally varied from sub- to multi-millimeter diameter (maximum $\sim 6 \mathrm{~mm}$ in plasma-fueling experiments), typically with a cylindrical shape and a length-over-diameter ratio (L/D) of less than 2. More recently, two new applications for the injection of cryogenic pellets have been identified, one for edge-localized mode (ELM) mitigation ${ }^{6-9}$ and another for plasma disruption mitigation. ${ }^{9-11}$ The gas gun model described here was specifically developed to help with the design and optimization of operating parameters of gas guns for the disruption mitigation application.

Plasma disruptions present a challenge for large tokamaks to withstand the intense heat flux, the large forces from halo and eddy currents in the structures, and the potential first wall damage from multi-MeV runaway electrons that form during the current decay. ${ }^{12}$ Injecting large quantities of materials such as $\mathrm{D}_{2}, \mathrm{Ne}$, Ar, or mixtures of them into the plasma during a disruption will reduce the plasma thermal energy by radiation losses and will increase its 
resistivity and electron density to mitigate the effects. Injection of massive amounts of gas directly from fast valves is used on several tokamaks (and some systems based on gas injection are planned for ITER ${ }^{13}$ ); however, the potential advantages of shattered pellets have also been recognized, and some have been demonstrated in disruption experiments on DIII-D. ${ }^{14-16}$ For large tokamaks the application of shattered-pellet mitigation requires larger pellets than those previously used in fusion research, and accordingly, the gas guns would require larger propellant valves (larger orifice diameter and volume) and longer gun barrels to provide the highest possible pellet speeds. The key objective is to inject large quantities of material into the plasma within a relatively short time (tens of milliseconds) ${ }^{11}$ from a precursor notice of an imminent disruption, and the pellet speed is the key parameter in determining the response time. For the ITER application, it is also necessary to limit the amount of propellant gas used for pellet acceleration due to constraints imposed by the torus vacuum cryopumps. The gas gun model provides a means to study the effects of all key parameters and to optimize gun performance for any practical operating scenarios and constraints.

The technology for forming, accelerating, and shattering large cryogenic pellets (up to $34 \mathrm{~mm}$ in diameter) have been under development for almost a decade at Oak Ridge National Laboratory (ORNL), and thorough descriptions of these techniques and operating procedures have been published. ${ }^{17-19}$ This method is often referred to as "shattered pellet injection" because the pellets need to be shattered immediately before entering the plasma to ensure that relatively large solid fragments do not survive and possibly damage first wall components. The shattering process also greatly enhances the surface area for enhanced ablation and assimilation in the hot plasma. A single-pellet pipe gun system based on this technology was installed on DIII-D in 2009 and has been successfully used in many plasma experiments to study/demonstrate the 
effectiveness of large shattered pellets to mitigate disruptions. ${ }^{14-16}$ Shattering of the pellets has proven to be straightforward and can be reliably accomplished with a simple bend or mechanism at the end of the transport tube. ${ }^{17,18}$ Only brief descriptions of the equipment and operations specifically relevant for the experimental data reported here are included in this article.

\section{DESCRIPTION OF GAS GUN MODEL/CODE}

The code represents a virtual model of the physical gun shown in Fig. 1. The fast-acting valve and closely coupled reservoir provide the propellant gas to accelerate a projectile through the barrel. Although the gun model is generic and could be used for any propellant type and projectile mass, the version presented here is configured to accommodate cryogenic pellets solidified from gases (typically $\mathrm{H}_{2}, \mathrm{D}_{2}, \mathrm{Ne}$, Ar, or mixtures of them). The pellet is formed inside a stainless tube and is cooled by a cryogenic refrigerator or by the direct flow of cold $\mathrm{He}$ (mechanically coupled through an oxygen-free high-thermal-conductivity copper ring). When the valve is opened, the propellant gas expands through an orifice into a vacuum to fill the breech volume and accelerate the pellet down the length of the barrel.

The code models this system by dividing the gun into three main regions as shown schematically in Fig. 2: the valve/reservoir (the total gas volume behind the seal on the valve orifice), the breech, and the pellet/barrel. The valve/reservoir volume initially contains the pressurized (40-70 bar) propellant gas while the breech/barrel volumes are initially evacuated. As the valve opens, the propellant expands into the breech and begins to fill it, raising the breech pressure. As the breech pressure rises, the force exerted on the rear of the pellet by the propellant gas also increases until it breaks away and begins to accelerate down the barrel. The propellant gas continues to expand as the pellet travels forward, keeping pressure and force acting on the 
rear of the pellet throughout the entire length of the barrel. The input and output parameters for the code are summarized in Table I, including a listing of input values (or ranges) studied here.

The mathematics behind this simulation are similar to those used by Milora ${ }^{20}$ in QUICKGUN, a model/code for modeling two-stage light gas guns. Unlike QUICKGUN, the present code models the gun as having only a single stage and takes into account the buildup of pressure in the breech before the pellet breaks away. The conditions of each region are tracked by the code during the simulation as gas and energy are exchanged. The flow of gas from the valve/reservoir volume to the breech is modeled as frictionless, adiabatic flow through a simple flat-plate orifice. The entire exchange is driven by several simple (zero-dimensional) gas flow equations, which are described by Milora in Sections 2.2 and 2.3 of his report. ${ }^{20}$ Because of the extremely short timescales involved (a typical shot takes less than $10 \mathrm{~ms}^{17,19}$ ), conservation of energy is assumed for these equations. As the breech volume continues to fill with propellant, the breech pressure increases. When the breech pressure exceeds the precalculated pellet breakaway pressure (discussed later in this section), the pellet breaks free from the walls and accelerates down the barrel. Because the expanding gas and pellet move at such high speeds, the effects of compression and rarefaction waves propagating from the breech and pellet must be considered. To take those effects into account, the code adopts the one-dimensional method suggested by Siegel $^{21}$ and described by Milora in Section 2.5 of his report. ${ }^{20}$ By assuming an average Mach number for the gas velocity in the gun breech, the one-dimensional method approximates the pressure at the base of the pellet as it travels down the barrel without explicitly considering the rarefaction waves that propagate rearward from the pellet. The equation of motion is then determined in terms of the base pressure $P_{p}$ and the mass $M_{p}$ and cross-sectional area of the projectile $A_{p}$ : 


$$
d U_{p} / d t=P_{p} * A_{p} / M_{p}
$$

To solve these equations, the code employs a stepwise approach. The code begins by determining the initial thermodynamic conditions of the entire gun based on user input parameters. At each time step the code calculates the parameters along the gun as shown in the schematic (Fig. 2) and then recalculates the pellet base pressure $P_{p}$, the pellet position $X_{p}$, and the velocity $U_{p}$. The simulation begins when the valve is opened and ends when the pellet leaves the barrel. The opening of the valve is assumed to be instantaneous in the model. The two valves ${ }^{22,23}$ used in the validation experiments reported here were fully opened within a few to several milliseconds after a trigger; the difference should have little effect on the overall gun performance.

The parameters of the gun are highly configurable. The energy of the propellant is controlled by the setup of the valve/reservoir. The energy of the propellant gas can be varied by changing the pressure, volume, temperature, and type of gas. However, the rate at which the energy can be released to the pellet depends on the extent to which the valve orifice (or optional downstream orifice plate) restricts the flow. This is determined primarily by the orifice diameter; two other variables, a maximum flow Mach number and a valve discharge coefficient, are also used to calculate the mass flow rate. As listed in Table I, values of 0.3 and 1.0 were used for the Mach number and the valve discharge coefficient, respectively, and are the same as those used by Milora. ${ }^{20}$ The calculated mass flow rate and gun performance are not very sensitive to minor changes of the Mach number or discharge coefficient.

The initial breech volume (the space between the rear of the pellet and the valve orifice/seal) can also be modified, although it has relatively little effect on gun performance for any practical values. A unique and very useful feature of the model is the capability to 
accommodate a wide range of pellet parameters specifically applicable for cryogenic pellets. The model can be configured for either shell pellets or mixed pellets. Shell pellets are composed of a dual layer, typically with a relatively thin $(<1 \mathrm{~mm})$ outer shell of $\mathrm{D}_{2}$ and a core of $\mathrm{Ne}$. The shear strength of $\mathrm{D}_{2}$ is significantly less than that of $\mathrm{Ne}$, and the thin layer of $\mathrm{D}_{2}$ allows the pellet to more easily break free from the walls of the barrel. Mixed pellets are formed (solidified) directly from a simple mixture of two gases (and maybe more). However, mixed pellets can require considerably more force to break free (especially as the concentration of the constituent with the higher shear strength increases). In either case, the L/D of the pellet must also be specified to set its dimensions and mass. Additionally, the final temperature of the pellet must be set, which affects how easily the pellet will break away from the barrel walls (shear strength of the cryogenic solids typically increase as the temperature decreases). While the "breakaway pressure" is usually calculated from $\mathrm{D}_{2}$ shear data reported by Fisher ${ }^{4,5}$ and Combs ${ }^{2}$ (Equation 3 in Ref. 2 calculates that pressure), it can also be entered in the code manually as an override feature. This is typically the case for mixed pellets or pure pellets of $\mathrm{Ne}$ or Ar because appropriate strength data are not readily available (and even more difficult to estimate as a function of temperature). Fortunately, the pellet speeds calculated from the code are not very sensitive to the breakaway pressure. It is critical to set the breakaway pressure low enough so that it will be exceeded during the simulation. Otherwise, the simulation will not proceed and will simply time out without yielding useful results. The length of the barrel (how far the pellet travels during acceleration) can then be configured. The value entered into the code is the length from the center of the pellet to the end of the acceleration tube; the code calculates the initial position of the base of the pellet, which is where the gas pressure is initially applied to provide the force for breaking the pellet away from the wall and subsequent acceleration. The simulation 
can be modified too; the step time (typically $0.5 \mu \mathrm{s}$ ) adjusts how far forward the simulation advances after each step while the maximum run time (typically $30 \mathrm{~ms}$ ) simply sets a time-out for the run. A code run usually takes no more than a few seconds to complete and produces an output file on a standard PC.

The code takes many parameters into account in a simulation, but it does not account for a few known phenomena. For instance, in relatively warm room-temperature barrels, cryogenic pellets tend to slightly ablate on the cylinder wall due to friction/heat transfer during initial acceleration. Although the resultant gas could contribute slightly to the pellet acceleration, gas blow-by around the pellet is probably a more significant effect and would be expected to reduce acceleration slightly as compared to a pellet that is always tightly sealed to the barrel wall. However, this would essentially eliminate any pellet/wall friction after the pellet is dislodged and moves slightly downstream. Also, the breakaway pressure calculations for mixed pellets are at best rough estimates because no useful shear data for solid Ne or Ar are readily available. However, actual test results presented later match simulation results closely enough so that the effect of these phenomena can be assumed to be relatively small, at least in the scope of this study.

Most of the relevant property data for the pure gases and cryogenic solids are readily available in the literature, with particularly useful information on the hydrogen isotopes consolidated and summarized by Souers. ${ }^{24}$ The simulation produces several outputs, the most useful of which is the muzzle velocity (or final pellet speed at the barrel exit). That value is the velocity at which the pellet is assumed to travel until it reaches the plasma, so it is crucial in determining response time to a plasma disruption event. For the supporting tests performed for 
this paper, muzzle velocities ranged from $\sim 200$ to $700 \mathrm{~m} / \mathrm{s}$. The code also tracks the state of the variables shown in Fig. 2 for the gun at specific time steps and stores the data to a spreadsheet.

\section{DESCRIPTION OF EXPERIMENTAL GAS GUNS}

Experimental pellet data from two gun barrels are included in the benchmark comparisons: $24.4 \mathrm{~mm}$ bore and $1.50 \mathrm{~m}$ acceleration length and $16.5 \mathrm{~mm}$ bore and $0.41 \mathrm{~m}$ acceleration length. Two valve types ${ }^{22,23}$ equipped with different orifice sizes were used to provide the propellant gas for the test data reported here. The simple valve illustrated in Fig. 1 is not an accurate representation of either valve, and the only features relevant for this study are the orifice sizes, the internal volumes for gas containment, and the speed at which the valves open (they open fully within a few to several milliseconds). One of the fast valves is relatively small ( $5 \mathrm{~mm}$ orifice and only $\sim 0.01 \mathrm{~L}$ internal volume); the other fast valve is relatively large (22 $\mathrm{mm}$ orifice and internal volume of $\sim 0.30 \mathrm{~L})$ and is a much better match for larger pellets $(>10 \mathrm{~mm}$ diam) because it can provide higher gas throughputs at any given pressure. The small orifice chokes the gas flow and thus limits pellet acceleration in the gun; that effect becomes more pronounced as the gun bore gets larger. For this study, both valves were normally equipped with a closely coupled reservoir to help keep the breech pressure elevated and to maximize the throughput during a shot, resulting in $0.30 \mathrm{~L}$ total volume for the small valve and $0.84 \mathrm{~L}$ for the large valve. Detailed information on both valves are available. ${ }^{22,23}$

\section{COMPARISON OF CODE RESULTS TO EXPERIMENTAL PELLET DATA}

The $24.4 \mathrm{~mm}$ diameter test pellets are only marginally smaller than the largest pellets planned for ITER $(28.5 \mathrm{~mm})$, and the $16.5 \mathrm{~mm}$ pellets are only slightly larger than the smallest ITER size $(13.4 \mathrm{~mm})$. If the model can adequately calculate the gun performance of these two pellet sizes for various configurations (physical and operating parameters), it should be 
applicable for all of the ITER large shattered pellets as well as for applications on other large tokamaks.

\section{IV.A. $24.4 \mathrm{~mm}$ Pellets}

The experimental speeds for the $24.4 \mathrm{~mm}$ pellets were obtained by measuring the time of flight between the output of a guide tube and a downstream target; the separation distance, $0.367 \mathrm{~m}$ and accurate within $\sim 1 \mathrm{~mm}$, has an almost negligible effect on the speed measurements. A high-speed camera operating at $\sim 36,000$ frames/s captured a movie of each pellet shot, and the pellet arrival time at each position could be determined within an accuracy of $\sim 1 / 2$ frame (or $\sim 15 \mu \mathrm{s})$. Assuming one frame $(\sim 30 \mu \mathrm{s})$ as the maximum error in determining the time of flight, the percentage of error in the speed measurement should be no more than $\sim 3 \%$ at $400 \mathrm{~m} / \mathrm{s}$ (directly proportional to the pellet speed). In Fig. 3 the pellet speeds calculated from the code are compared to experimental data for different valve orifice sizes at an operating pressure of 42.4 bar (very close to the 40 bar expected for the ITER application). The small and large test valves as described above were used to collect the experimental data for $5 \mathrm{~mm}$ and $22 \mathrm{~mm}$ orifice sizes. The large valve was also utilized for the $10 \mathrm{~mm}$ and $16.5 \mathrm{~mm}$ data; orifice plates were placed between the actual valve orifice and the pellet, as shown as an option in Fig. 1. It was not practical to build two additional valves for this study, and the approach taken should approximate the performance that would be achieved with valves equipped with the two smaller orifice diameters. Experimental data and model calculations are shown for both shell and mixed pellets ( $\mathrm{L} / \mathrm{D} \sim 1.2-1.6)$, with the mass varying by a factor of almost 2 . Although many of the experimental parameters did not vary much from shot to shot, the specific parameters for each test were used in the calculations. The small valve ( $5 \mathrm{~mm}$ orifice) was not able to provide enough gas pressure to dislodge the mixed gas pellet at $\sim 40$ bar. That outcome is not at all surprising because the breakaway pressure can be relatively high for mixed-gas pellets. As shown in Fig. 3, 
the agreement between the code calculations and the experimental speeds is excellent, never differing by more than $\sim 5 \%$. A second set of data was collected with these orifice sizes, and the only change was to increase the valve operating pressure to $\sim 60$ bar. Again, the agreement between model and experiment, shown in Fig. 4, is excellent. Both the code results and the experimental data indicate that there is no discernible improvement in performance between the 16.5 and $22.0 \mathrm{~mm}$ orifice sizes.

The total volume of the valve, including any closely coupled reservoirs, is another key parameter in determining gun performance. A special series of tests, in which the volume was varied, were carried out with the large valve (no secondary orifice plate). The large valve was designed to accommodate two reservoirs, and the standard configuration includes one $\sim 0.5 \mathrm{~L}$ vessel (total volume $=0.84 \mathrm{~L}$ ). A second vessel of similar size was added for some limited test shots (total volume $=1.62 \mathrm{~L})$. Also, several test shots were made with no reservoir attached (total volume $=0.30 \mathrm{~L}$ ). In Fig. 5 the pellet speeds calculated from the code are compared to experimental data for different valve volumes at an operating pressure of 42.4 bar. The agreement between the code calculations and the experimental speeds is noteworthy for the two large volumes ( $<8 \%$ difference); however, the calculated speeds do not match the experimental speeds very well for the smallest volume (calculated values are $\sim 25 \%$ to $30 \%$ greater than those measured). The reason is not apparent; it could be that the valve volume is less than the estimation and that the calculation is very sensitive to such volumes (as relative to that in the gun breech and barrel). In any case, the $0.3 \mathrm{~L}$ is not a practical volume and would never be used with larger valves/guns if high pellet speeds are the main objective.

\section{IV.B. $16.5 \mathrm{~mm}$ Pellets}

The only key gas gun parameters that were not varied in Figs. 3, 4, and 5 are the pellet diameter, the gun barrel length, and the propellant gas. In Fig. 6, experimental data ${ }^{19}$ and model 
calculations are compared from test shots with $16.5 \mathrm{~mm}$ pellets and a different barrel length and propellant gas. The gun barrel length for these experiments was $0.41 \mathrm{~m}$, and the propellant gas was $\mathrm{H}_{2}$ (He was the propellant gas used for the data shown in Figs. 3-5). The experimental pellet speeds were obtained by measuring the time of flight between the gun barrel muzzle and a downstream microwave cavity mass detector ${ }^{17}$ (separation distance $=1.110 \mathrm{~m}$ and accurate to within $\sim 2 \mathrm{~mm}$ ). The same high-speed camera that was used to record the $24.4 \mathrm{~mm}$ pellets was used to record a movie at the gun muzzle only, and the timing of the pellet at that position could also be estimated within $\sim 15 \mu$ s. The peak signal from the microwave cavity upon a pellet's passing through it provided precise timing data for the pellet arrival at the cavity center; assuming $15 \mu$ s for the accuracy of this timing data is conservative since the data acquisition system operated at $1 \mathrm{MHz}$ (or a sample every $1 \mu \mathrm{s}$ ). Using $30 \mu \mathrm{s}$ as the maximum total error in determining the time of flight (as for the $24.4 \mathrm{~mm}$ pellets), the percentage of error in the speed measurement should be no more than $\sim 1 \%$ at $400 \mathrm{~m} / \mathrm{s}$ (also directly proportional to the pellet speed). The error estimate is lower than that for the previous case ( $24.4 \mathrm{~mm}$ pellets) because the pellet speed is evaluated over a longer distance, and thus the measured travel time is significantly longer with approximately the same uncertainty in the measurement.

The data shown in Fig. 6 are for pellets formed from a mixed gas $\left(\mathrm{Ne} / \mathrm{D}_{2}\right)$, and the speeds are plotted against mole percentage of Ne. A set of speed data was collected with each of the two propellant valves, with an operating pressure of 42.4 bar with the large valve and 70.0 bar with the small valve. Using the higher pressure with the small valve produced experimental speeds approaching those attained with the larger valve. In general, the calculated speeds from the model are in good agreement with the experimental speed data (usually within $10 \%$ or less). The 
code mimics the experimental data shown in Fig. 6 remarkably well, given that the pellet mass varies by a factor of $>5$ and that two valves were used at different operating pressures.

\section{DISCUSSION}

Both the code results and the experimental data with the $24.4 \mathrm{~mm}$ pellets (Figs. 3 and 4) indicate that there is no discernible improvement in performance between the 16.5 and $22.0 \mathrm{~mm}$ orifice sizes. Similarly, even doubling of the valve/reservoir volume (from $\sim 0.8$ to $1.6 \mathrm{~L}$ in Fig. 5) only resulted in $\sim 10 \%$ increase in the pellet speed. This suggests that the valve size could probably be reduced somewhat for large pellets and not appreciably affect the pellet speed. The pellet speed was observed to increase by $\sim 20 \%$ by increasing the valve pressure from $\sim 40$ bar to $\sim 60$ bar (Figs. 3 and 4); however, that would not be an option for the ITER application because the operating pressure has essentially been fixed at 40 bar.

Injection of multiple large shattered pellets (up to $\sim 30$ are included in the present design) will be needed to quench the large ITER plasmas. The present scheme includes a mix of four pellet sizes ranging from 13.4 to $28.5 \mathrm{~mm}$ in diameter. The speed to which the largest (and thus heaviest) pellets can be accelerated will be somewhat limited (as compared to the other smaller sizes), with the given constraints on the pressure and volume of the valve and the barrel length. The present design also dictates that the $28.5 \mathrm{~mm}$ pellets be relatively long (up to $\mathrm{L} / \mathrm{D}=2$ ). Because pellets of that size ( $\sim 50 \mathrm{~g}$ for shell pellets) will typically be the slowest, a code run was made to calculate the performance for a practical operating scenario with that pellet mass. In Fig. 7 the inputs for the code run are listed, and three of the key code outputs are plotted against time. The propellant valve parameters (orifice size $=24.5 \mathrm{~mm}$ and volume $=1.15 \mathrm{~L}$ ) are the design values for a new valve under development at ORNL specifically for ITER shattered pellet injection systems. Likewise, the breech volume $(0.25 \mathrm{~L})$ and the barrel length $(1.1 \mathrm{~m})$ are values 
from a preliminary ITER pipe gun design. In the top plot of Fig. 7 (a), the pressure on the base of the pellet is shown from the time of the valve opening until the pellet exits the barrel ( 8.4 ms). As shown in Fig. 7 (b and c), the pellet does not start to accelerate until the breakaway pressure ( 27 bar) is reached, and the speed increases steadily as it accelerates down the barrel until it exits with a muzzle velocity of $247 \mathrm{~m} / \mathrm{s}$. This result is for a shell pellet with a $0.7 \mathrm{~mm} \mathrm{D}_{2}$ layer on the outer rim and a total mass of $48.2 \mathrm{~g}(98.5 \% \mathrm{Ne})$. The code calculates a pressure of $16.5 \mathrm{bar}$ in the valve/reservoir volume when the pellet exits the barrel. Since the valve closure will take some time and cannot be reliably characterized at this time, it is assumed that all of the propellant gas will be exhausted on each shot in ITER operations. For comparison, a code run was made (not shown here) in which the only change was to replace the valve orifice diameter with a smaller value. A value of $16.5 \mathrm{~mm}$ was selected because it appears to be the optimal size tested with the large valve used in the experiments reported here (Figs. 3 and 4). With the smaller orifice, the calculated muzzle velocity was $240 \mathrm{~m} / \mathrm{s}$ or only $\sim 3 \%$ less than with the substantially larger $24.5 \mathrm{~mm}$ orifice. Another code run was made using the $16.5 \mathrm{~mm}$ valve orifice size and only reducing the valve volume from 1.15 to $1.00 \mathrm{~L}$, and the calculated speed only decreased $\sim 2 \%$ more (to $235 \mathrm{~m} / \mathrm{s}$ ). Overall, the calculated pellet speed only dropped $\sim 5 \%$ with a significant reduction in the valve orifice size $(24.5$ to $16.5 \mathrm{~mm})$ and a modest decrease in the valve volume $(1.15$ to $1.00 \mathrm{~L})$. This supports the argument that the size of the valve could probably be reduced somewhat without sacrificing too much in gun performance. This could be a significant advantage because less energy (voltage-current product of power supply) would be required to open the valve and the footprint of the valve and power supplies could possibly be reduced. Given the relatively large number of valves required for this application $(\sim 30)$, reducing 
the size of the valves could result in lower fabrication costs and could help with some technical issues (limited space for installation and lower gas loads of propellant).

Pellet speed is the key performance parameter of the gas guns for ITER shattered pellets, and most of the operating parameters are essentially fixed (or very limited variability) for that application. The barrel length will be limited ( 1 m maximum) by physical constraints dictated by the installation. In any case, more propellant gas would be required to efficiently utilize the extra barrel length. The limit on the amount of propellant gas has already been mentioned and further reduces the benefit from extra barrel length. An attractive technique to attain higher pellet speeds without changing any of the other parameters is to increase the percentage of the lighter $\mathrm{D}_{2}$ species in the pellet. For example, a code run similarly to that shown in Fig. 7 indicated that reducing the pellet mass to $12.7 \mathrm{~g}$ by adding more $\mathrm{D}_{2}$ to the composition $\left(50 \% \mathrm{Ne} / 50 \% \mathrm{D}_{2}\right.$ by mass) increased the muzzle velocity from 247 to $439 \mathrm{~m} / \mathrm{s}$ (or $\sim 80 \%$ faster). With constraints on both the total amount of $\mathrm{He}$ and $\mathrm{D}_{2}$ injected into ITER from shattered pellet injection systems, a practical approach would be to use the He supply as propellant and $\mathrm{D}_{2}$ supply for pellets. This is an effective way and perhaps the best option to attain higher speeds if pellets with lower $\mathrm{Ne}$ concentrations are adequate to meet the technical objectives. In recent plasma disruption experiments with shattered pellets on DIII-D, Shiraki et al. ${ }^{16}$ found that relatively small quantities of the radiating impurity $(\mathrm{Ne})$ can provide effective thermal mitigation. The pellet mass can also be decreased by utilizing shorter pellets of any composition (L/D $=1$ is usually the minimal practical limit), and this can result in significant increases in the pellet speed (depending on how much the pellet length or weight decreases). The code can be used to estimate gas gun performance for any set of physical and operating parameters. This is illustrated in Figs. 8 through 11, in which calculated speeds are plotted against the barrel length for four different 
valve orifice sizes. For all of these calculations the propellant gas is $\mathrm{He}$ at $40 \mathrm{bar}$, and the valve volume is $1.0 \mathrm{~L}$. Figures 8 and 9 are calculated speeds for the smallest $(13.4 \mathrm{~mm})$ pellet size planned for ITER, and Figs. 10 and 11 show data for the largest $(28.5 \mathrm{~mm})$ pellet size planned for ITER. Calculations are presented for both types of pellets discussed here, the heavier shell pellets and the lighter pellets formed from a mixed gas $\left(50 \% \mathrm{Ne} / 50 \% \mathrm{D}_{2}\right.$ by moles $)$. From these plots, the gun performance can easily be compared for any combination of valve orifice size and barrel length. Choosing an orifice size of $20 \mathrm{~mm}$ and a barrel length of $1.0 \mathrm{~m}$, the calculated speeds vary from $\sim 240 \mathrm{~m} / \mathrm{s}$ for the heaviest pellets (Fig. 11) to $\sim 560 \mathrm{~m} / \mathrm{s}$ for the lightest pellets (Fig. 8).

\section{SUMMARY}

A gas gun model/code has been developed at ORNL, and the present version is configured specifically for pipe guns that will be used to provide large cryogenic pellets (13.4 to $28.5 \mathrm{~mm}$ diameter) at high speeds for the ITER shattered pellet injection systems. The pellet speed is the key parameter in determining the response time of a shattered pellet system to a plasma disruption event, and approximating the gun performance with a model/code was the motivation for this study. In the pipe gun injectors, fast-acting valves provide the light gas to accelerate the cryogenic pellets in stainless steel tubes. For the ITER application, the pellets will be composed of solid $\mathrm{D}_{2}, \mathrm{Ne}$, Ar, or mixtures of them; and the propellant gas will most likely be He (40 bar supply pressure). The model/code has been benchmarked against experiments over a wide range of physical and operating parameters, including different propellant valve configurations (gas type, pressure, orifice size, and volume), different pellets (type/composition, diameter, length, and weight), different barrel lengths, and different breech volumes. The two pellet sizes used in the experiments were 16.5 and $24.4 \mathrm{~mm}$ and are relevant for the ITER 
application, with the test pellet sizes falling between the smaller and larger ITER sizes. For the vast majority of experiments, the calculated pellet speeds from the code were in excellent agreement with the measured values (speeds $\sim 200$ to $700 \mathrm{~m} / \mathrm{s}$ ).

Multiple shattered pellet injection systems equipped with up to $\sim 30$ pellets in total are included in the present ITER design as one of the crucial systems to help mitigate plasma disruptions. The objective is to inject the material into the plasma within the shortest possible time (within $\sim 10$ to $20 \mathrm{~ms}$ is desirable and challenging). ${ }^{11}$ The pellets for ITER will travel $\sim 6 \mathrm{~m}$ from the pellet formation position to the shattering spot located near the machine wall/plasma interface. Given the present propellant valve and gun barrel designs for the ITER application, the model $/$ code indicates that the slowest expected pellet speed will be $\sim 250 \mathrm{~m} / \mathrm{s}$ for the largest and most massive pellets. Code results suggest that the best options for increasing this relatively low speed are to decrease the mass by either adding more $\mathrm{D}_{2}$ to the pellet composition (and maintaining the pellet length) or decreasing the pellet length (less overall particles in this case). No results with Ar as a constituent of the pellets are presented here because it has been an experimental challenge to add Ar to the pellet mix (due to large difference in temperature triple points). This model/code has already been used to help in the early design of the ITER shattered pellet injection systems and should prove even more valuable in the future as the designs and operating parameters are finalized.

This study only evaluated experimental data and code results for pellet sizes relevant for mitigation of ITER disruptions, the model/code should be applicable for any practical light gas gun configuration. In limited analyses of some previous ORNL pellet injection systems, ${ }^{2}$ it was found that the model/code was also able to provide adequate estimates of gun performance for pellet sizes in the range of $\sim 2$ to $10 \mathrm{~mm}$ in diameter. 


\section{Acknowledgments}

The authors would like to especially thank Stan Milora for his contributions. His previous work and ideas regarding high-velocity gas guns greatly improved the quality of the code and this research. The model/code described here is fashioned in large part upon his "QUICKGUN" model for two-stage light gas guns, which has been used and appreciated by many researchers around the world.

\section{References}

1. S. L. Milora, "Review of Pellet Fueling," J. Fusion Energy, 1, 15 (1981).

2. S. K. Combs, "Pellet Injection Technology," Rev. Sci. Instrum., 64, 1679 (1993).

3. S. L. Milora et al., "Pellet Fueling," Nucl. Fusion, 35, 657 (1995).

4. P.W. Fisher, "Tritium Proof-of-Principle Pellet Injector," Oak Ridge National Laboratory Report, ORNL/TM-11781 (1991).

5. P. W. Fisher, "Properties of Tritium Inferred from Pellet Injector Experiments," Fusion Technol., 21, 794 (1992).

6. P.T. Lang et al., "ELM Pace Making and Mitigation by Pellet Injection in ASDEX Upgrade," Nucl. Fusion, 44, 665 (2004).

7. L. R. Baylor et al., "Reduction of Edge-Localized Mode Intensity Using High-RepetitionRate Pellet Injection in Tokamak H-Mode Plasmas,” Phys. Rev. Lett., 110, 245001 (2013).

8. L. R. Baylor et al., "ELM Mitigation with Pellet ELM Triggering and Implications for PFCs and Plasma Performance in ITER," Journal of Nuclear Materials, 463, 104 (2015).

9. L.R. Baylor et al., Pellet Fueling, ELM Pacing and Disruption Mitigation Technology Development for ITER, Nucl. Fusion, 49, 085013 (2009). 
10. L. R. Baylor et. al, "Disruption-Mitigation-Technology Concepts and Implications for ITER,” IEEE Trans. Plasma Sci., 38 (3), 419 (2010)

11. L. R. Baylor et. al, "Disruption Mitigation System Development and Design for ITER," Fusion Science and Technology, 68, 211 (2015).

12. A. Loarte et. al, ITER Physics Basis - "Chapter 4: Power and Particle Control," Nucl. Fusion, 47, S203 (2007).

13. M. Lehnen et al., "Disruptions in ITER and Strategies for Their Control and Mitigation," Journal of Nuclear Materials, 463, 39 (2015).

14. N. Commaux et al., "Demonstration of Rapid Shutdown Using Large Shattered Deuterium Pellet Injection in DIII-D,” Nucl. Fusion, 50, 112001 (2010).

15. N. Commaux et al., "First Demonstration of Rapid Shutdown Using Neon Shattered pellet Injection for Thermal Quench Mitigation on DIII-D,” Nucl. Fusion, 56, 046007 (2016).

16. D. Shiraki et al., "Thermal Quench Mitigation and Current Quench Control by Injection of Mixed Species Shattered Pellets in DIII-D,” Phys. Plasmas, 23, 062516 (2016).

17. S. K. Combs et al., "Alternative Techniques for Injecting Massive Quantities of Gas for Plasma-Disruption Mitigation,” IEEE Trans. Plasma Sci., 38 (3), 400 (2010).

18. S.K. Combs, et al., "A Technique for Producing Large Dual-Layer Pellets in Support of Disruption Mitigation Experiments," Fusion Science and Technology, 60(2), 473 (2011).

19. S.K. Combs et al., "Solidification and Acceleration of Large Cryogenic Pellets Relevant for Plasma Disruption Mitigation,” in press (IEEE Trans. Plasma Sci.).

20. S. L. Milora et al., "QUICKGUN: An Algorithm for Estimating the Performance of TwoStage Light Gas Guns,” Oak Ridge National Laboratory Report, ORNL/TM-11561 (1990). 
21. A. E. Siegel, “The Theory of High Speed Guns," NATO AGARDograph 91, North Atlantic Treaty Organization, 1965 (Technical Report available from Defense Technical Information Center, Defense Logistics Agency, Alexandria, Virginia).

22. S. L. Milora, S. K. Combs, and C. R. Foust, "Fast-Opening Magnetic Valve for HighPressure Gas Injection and Applications to Hydrogen Pellet Fueling Systems," Rev. Sci. Instrum., 57, 2356 (1986).

23. S. K. Combs, C. R. Foust, and M. J. Gouge, "Fast-Opening High-Throughput Gas Valve and Application for Inertial Fusion Energy R\&D,” Rev. Sci. Instrum., 75, 270 (2004).

24. P. C. Souers, Hydrogen Properties for Fusion Energy, Univ. California Press, Berkley, 1986.

\section{List of Tables}

Table I. Parameters for Gas Gun Simulator Code (Input Values for Study Are Listed)

\section{List of Figures}

Fig.1. Schematic of a cryogenic pipe gun with fast-acting propellant valve.

Fig. 2. Schematic representation of single-stage gas gun model (symbols defined in Ref. 20).

Fig. 3. Comparison of experimental gun $(24.4 \mathrm{~mm}$ bore $\times 1.5 \mathrm{~m}$ long) performance and code results for different valve orifice diameters at an operating pressure of $\sim 40$ bar.

Fig. 4. Comparison of experimental gun $(24.4 \mathrm{~mm}$ bore $\times 1.5 \mathrm{~m}$ long) performance and code results for different valve orifice sizes at an operating pressure of $\sim 60$ bar.

Fig. 5. Comparison of experimental gun $(24.4 \mathrm{~mm}$ bore $\times 1.5 \mathrm{~m}$ long) performance and code results for different valve volumes at an operating pressure of $\sim 40$ bar (large propellant valve with $22 \mathrm{~mm}$ orifice). 
Fig. 6. Comparison of experimental gun ( $16.5 \mathrm{~mm}$ bore $\times 0.41 \mathrm{~m}$ long) performance and code results for a wide range of pellet mixtures $\left(\mathrm{Ne} / \mathrm{D}_{2}\right)$ and two different propellant valves (and operating pressures).

Fig. 7. Model/code results for the largest pellet $(28.5 \mathrm{~mm})$ planned for the ITER shattered pellet injection systems. The valve volume and orifice diameter match those of a valve under development specifically for the ITER application.

Fig. 8. Effects of propellant valve orifice size and barrel length on pellet speed for $13.4 \mathrm{~mm}$ pellets formed from mixed gas (smallest size planned for ITER).

Fig. 9. Effects of propellant valve orifice size and barrel length on pellet speed for $13.4 \mathrm{~mm}$ shell pellets (smallest size planned for ITER).

Fig. 10. Effects of propellant valve orifice size and barrel length on pellet speed for $28.5 \mathrm{~mm}$ pellets formed from mixed gas (largest size planned for ITER).

Fig. 11. Effects of propellant valve orifice size and barrel length on pellet speed for $28.5 \mathrm{~mm}$ shell pellets (largest size planned for ITER). 


\section{TABLE I.}

Parameters for Gas Gun Simulator Code (Input Values for Study Are Listed)

\begin{tabular}{|c|c|}
\hline Inputs & $\begin{array}{l}\text { Outputs } \\
\text { (calculated for each time step) }\end{array}$ \\
\hline Valve and Reservoir & Valve and Reservoir \\
\hline Total Gas Volume $\left[\mathrm{V}_{\mathrm{r}}\right]$ & Pressure $\left[P_{r}\right]$ \\
\hline Propellant Gas (Select $\mathrm{He}, \mathrm{H}_{2}$, or & Moles of Gas \\
\hline \multirow{2}{*}{$\begin{array}{l}\text { Initial Pressure }\left[P_{r}\right] \\
\text { Initial Temperature }\left[T_{r}\right]\end{array}$} & Gas Temperature $\left[T_{r}\right]$ \\
\hline & Mass Flow Rate $\left[\overline{\mathcal{M}}_{\mathrm{b}}\right]$ \\
\hline Orifice Diameter & Breech \\
\hline Maximum Mach Number & Pressure $\left[P_{b}\right]$ \\
\hline Discharge Coefficient & Moles of Gas \\
\hline Pellet & Gas Temperature $\left[T_{b}\right]$ \\
\hline \multirow{2}{*}{$\begin{array}{l}\text { Pellet Type (Select Shell or Mixed Gas) } \\
\text { Shell - Thickness of Outer Layer (mm) } \\
\text { Mixed Gas - Molar Fractions }\left(\mathrm{D}_{2}, \mathrm{Ne} \text {, and } \mathrm{Ar}\right)\end{array}$} & Pellet \\
\hline & Base Pressure $\left[P_{p}\right]$ \\
\hline Temperature $\left[T_{p}\right]$ & Position $\left[X_{p}\right]$ \\
\hline $13.4-28.5 \mathrm{~mm}$ & Velocity $\left[\mathrm{U}_{\mathrm{p}}\right]$ \\
\hline Length/Diameter Ratio [L/D] & Acceleration \\
\hline Breakaway Pressure & \multirow{7}{*}{$\begin{array}{l}\text { Note: } \\
\text { - Code calculations stop when pellet } \\
\text { reaches end of barrel (or times out) } \\
\text { - Muzzle velocity } U_{p} \text { is the final pellet } \\
\text { speed at barrel exit } \\
\text { *Barrel length is distance from center } \\
\text { of pellet to end of the acceleration } \\
\text { tube; code calculates position of pellet } \\
\text { base where gas pressure is applied to } \\
\text { provide the force for breaking the } \\
\text { pellet away from the wall and } \\
\text { acceleration }\end{array}$} \\
\hline Gun & \\
\hline Breech Volume $\left[\mathrm{V}_{0}\right]$ & \\
\hline Barrel Length* & \\
\hline Simulation & \\
\hline Step Time & \\
\hline Maximum Run Time & \\
\hline
\end{tabular}




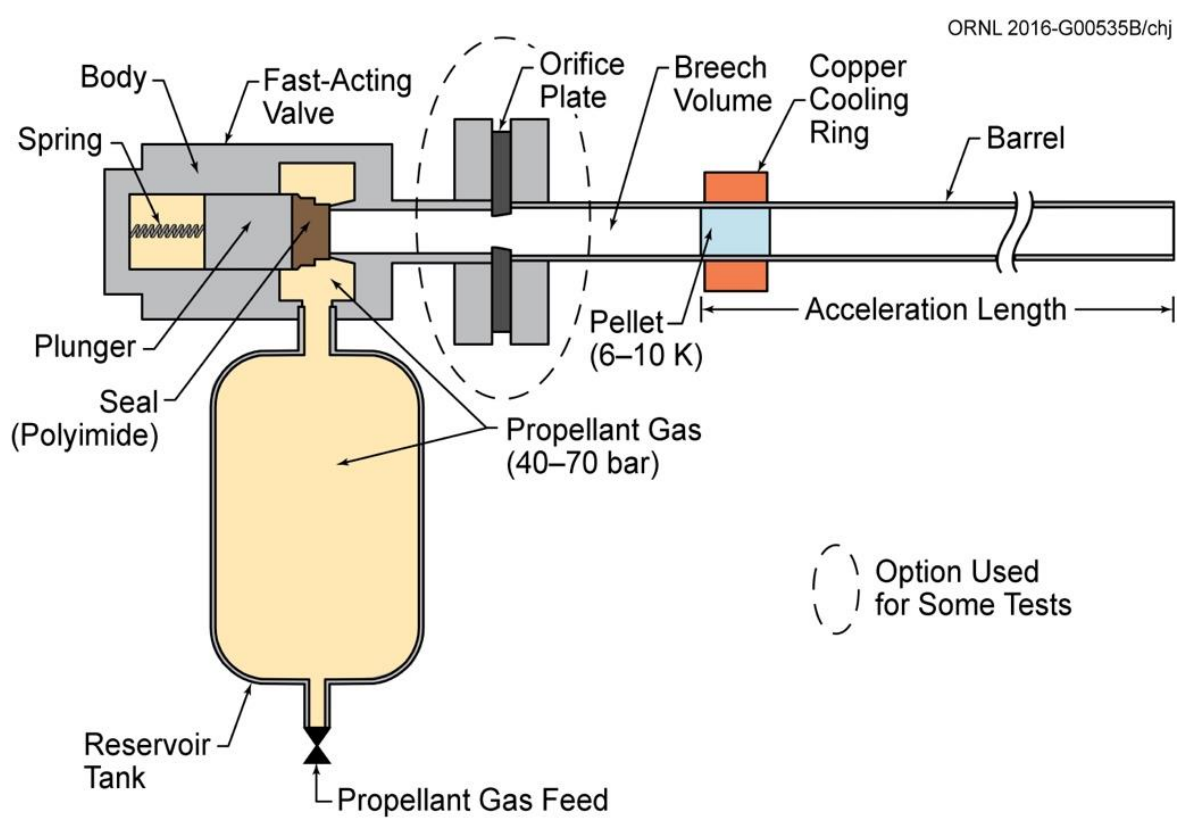

Fig.1. Schematic of a cryogenic pipe gun with fast-acting propellant valve.

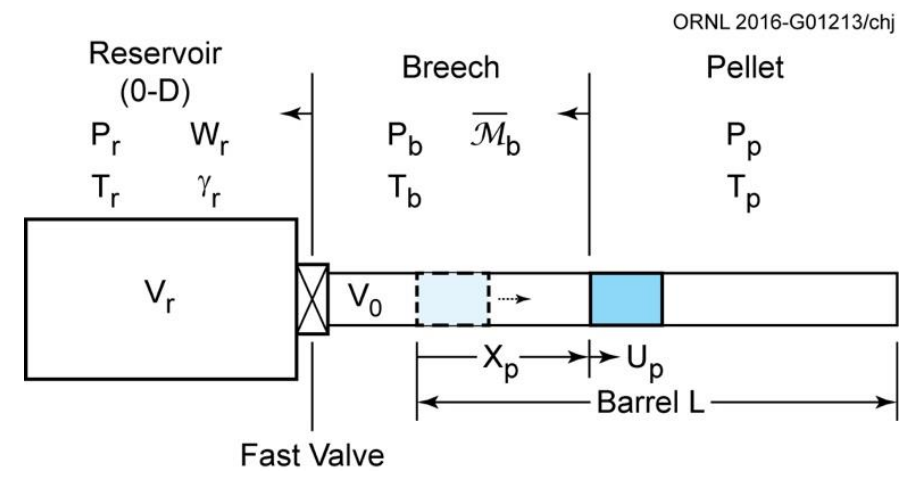

Fig. 2. Schematic representation of single-stage gas gun model (symbols defined in Ref. 20). 


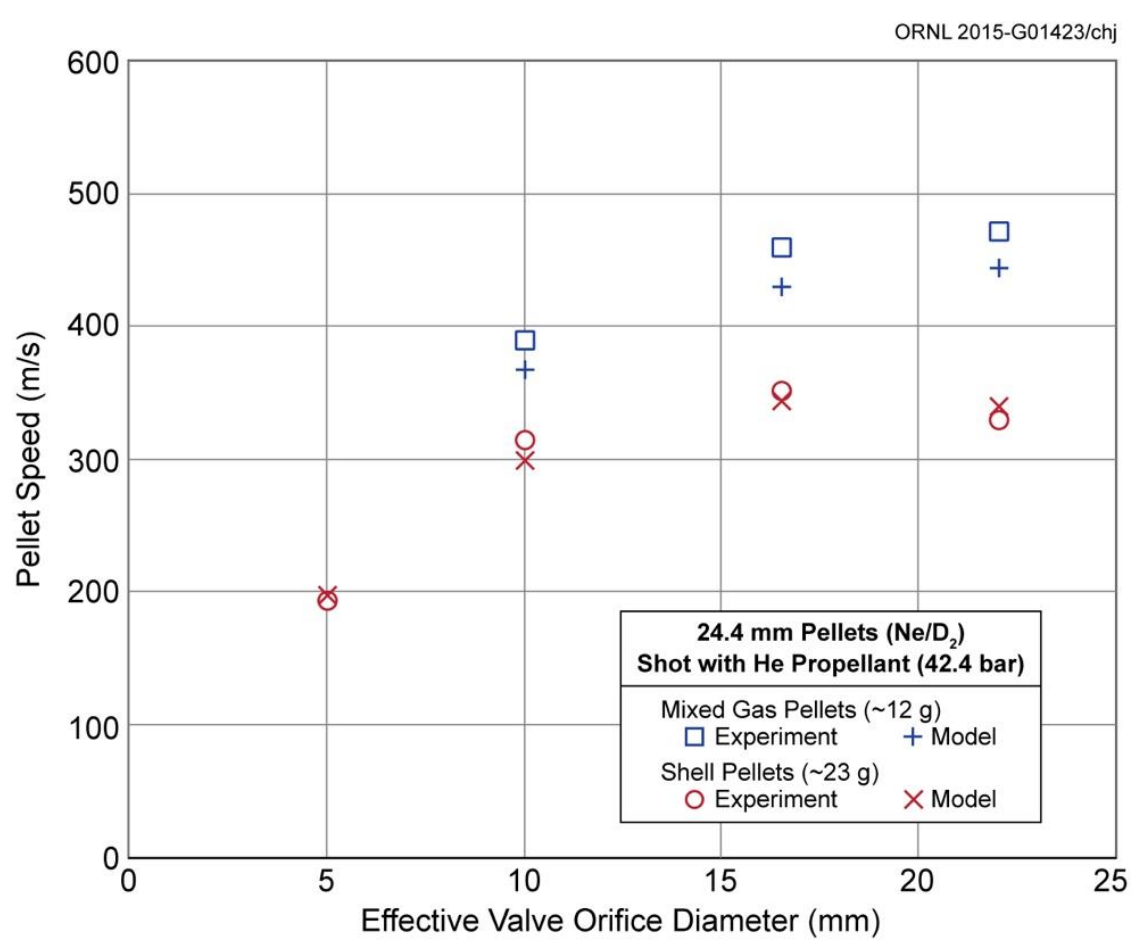

Fig. 3. Comparison of experimental gun $(24.4 \mathrm{~mm}$ bore $\times 1.5 \mathrm{~m}$ long $)$ performance and code results for different valve orifice diameters at an operating pressure of $\sim 40 \mathrm{bar}$.

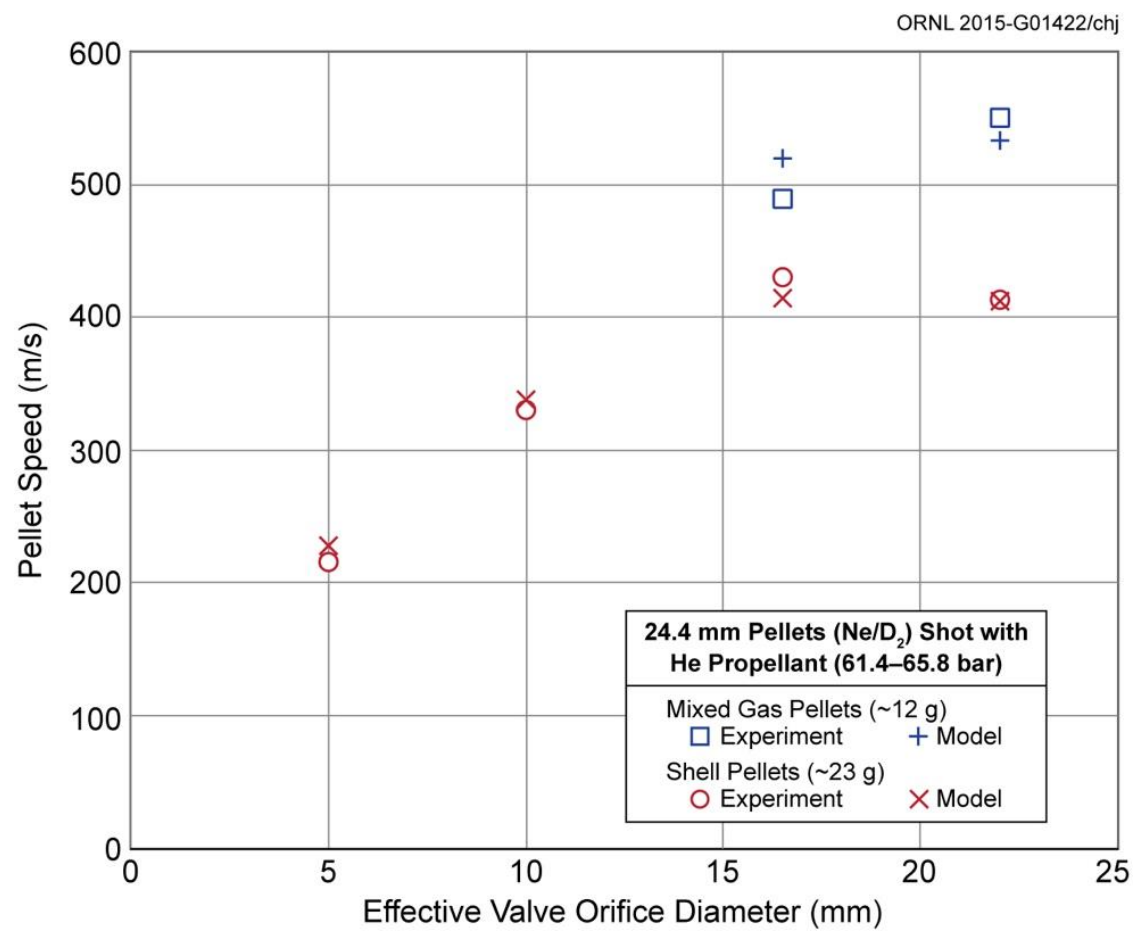

Fig. 4. Comparison of experimental gun $(24.4 \mathrm{~mm}$ bore $\times 1.5 \mathrm{~m}$ long $)$ performance and code results for different valve orifice sizes at an operating pressure of $\sim 60 \mathrm{bar}$. 


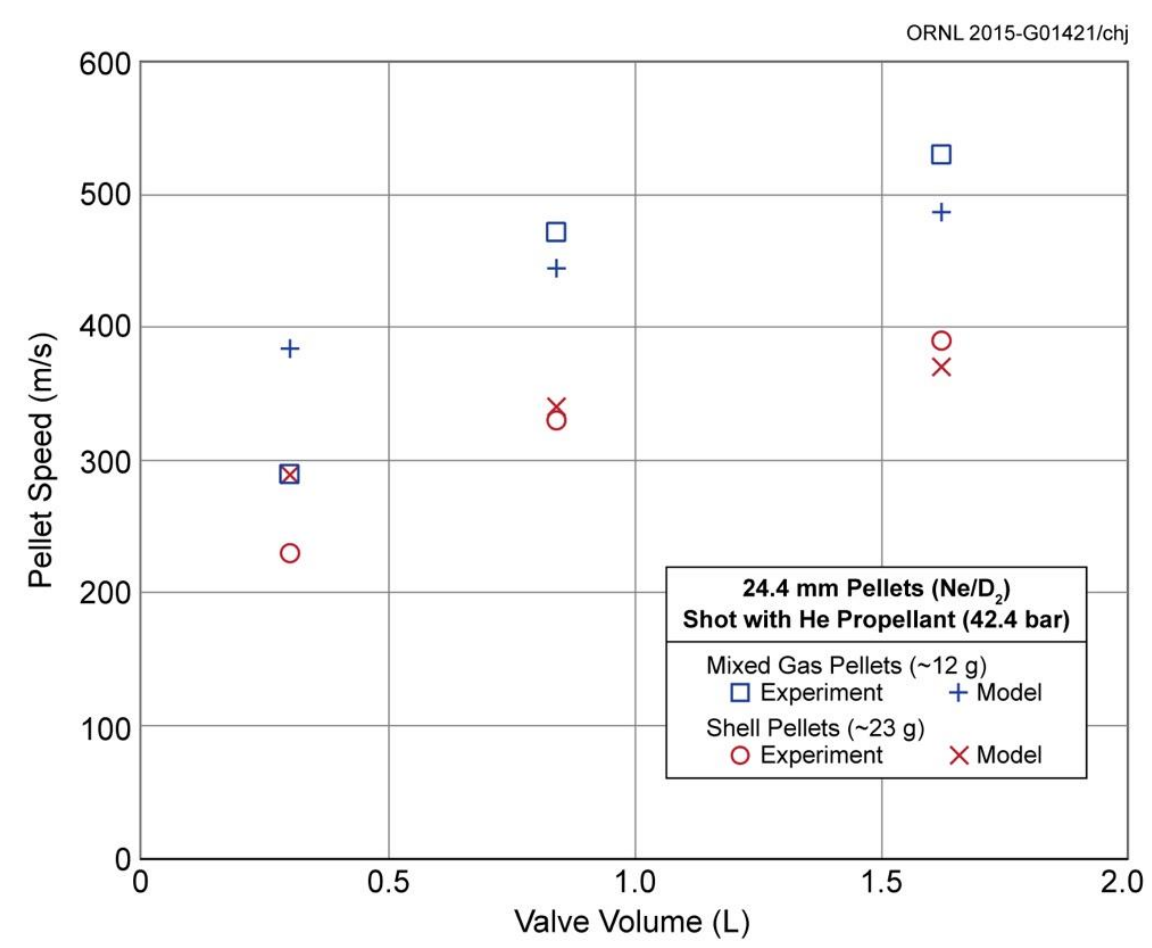

Fig. 5. Comparison of experimental gun performance $(24.4 \mathrm{~mm}$ bore $\times 1.5 \mathrm{~m}$ long) and code results for different valve volumes at an operating pressure of $\sim 40$ bar (large propellant valve with $22 \mathrm{~mm}$ orifice).

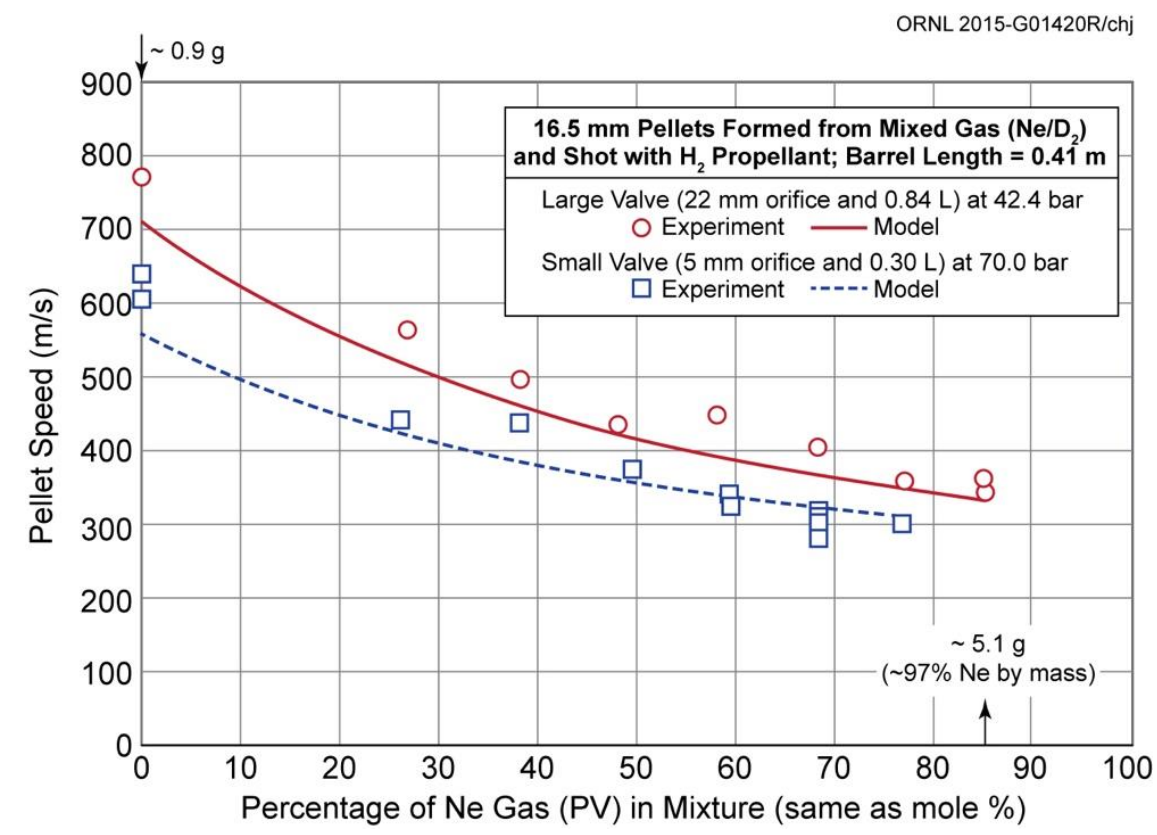

Fig. 6. Comparison of experimental gun $(16.5 \mathrm{~mm}$ bore $\times 0.41 \mathrm{~m}$ long) performance and code results for a wide range of pellet mixtures $\left(\mathrm{Ne} / \mathrm{D}_{2}\right)$ and two different propellant valves (and operating pressures). 

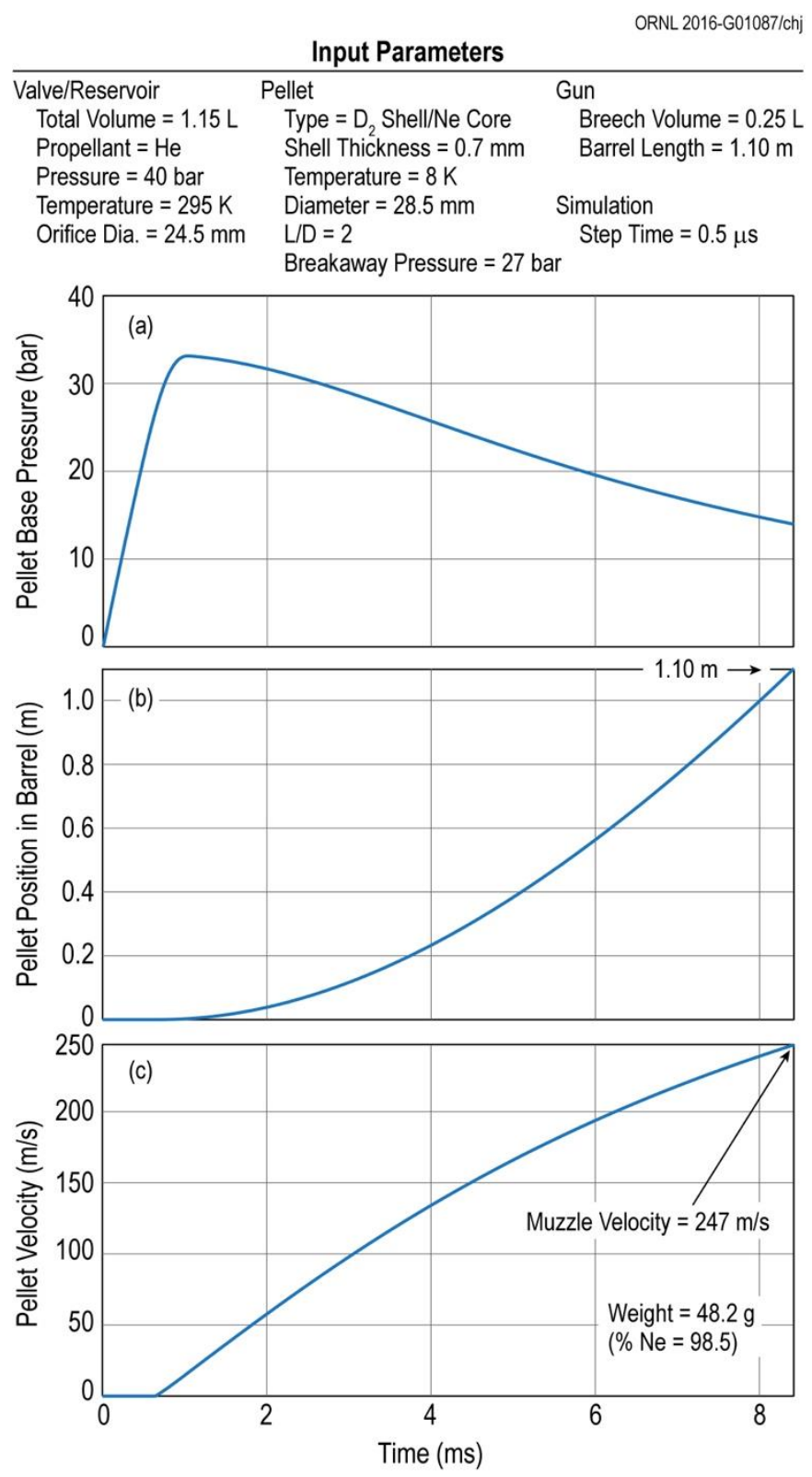

Fig. 7. Model/code results for the largest pellet $(28.5 \mathrm{~mm})$ planned for the ITER shattered pellet injection systems. The valve volume and orifice diameter match those of a valve under development specifically for the ITER application. 


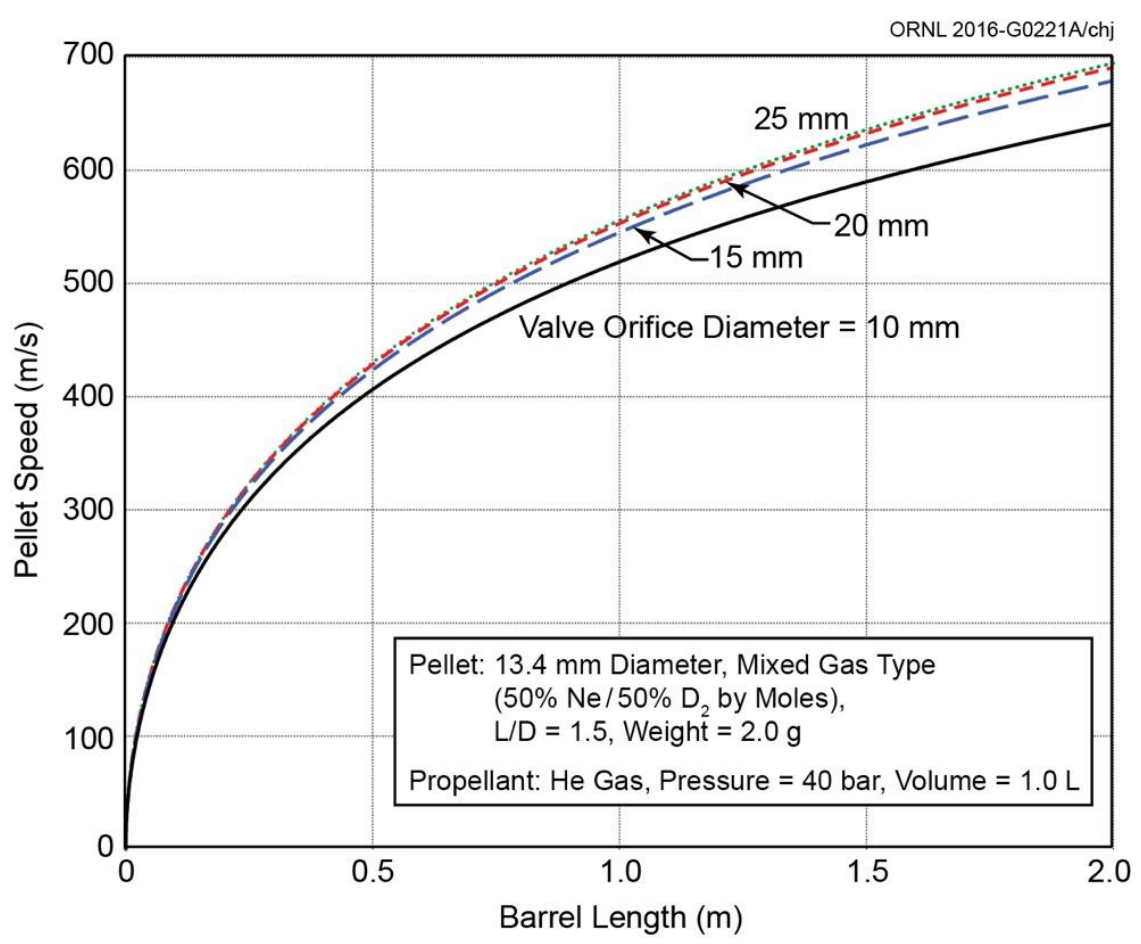

Fig. 8. Effects of propellant valve orifice size and barrel length on pellet speed for $13.4 \mathrm{~mm}$ pellets formed from mixed gas (smallest size planned for ITER).

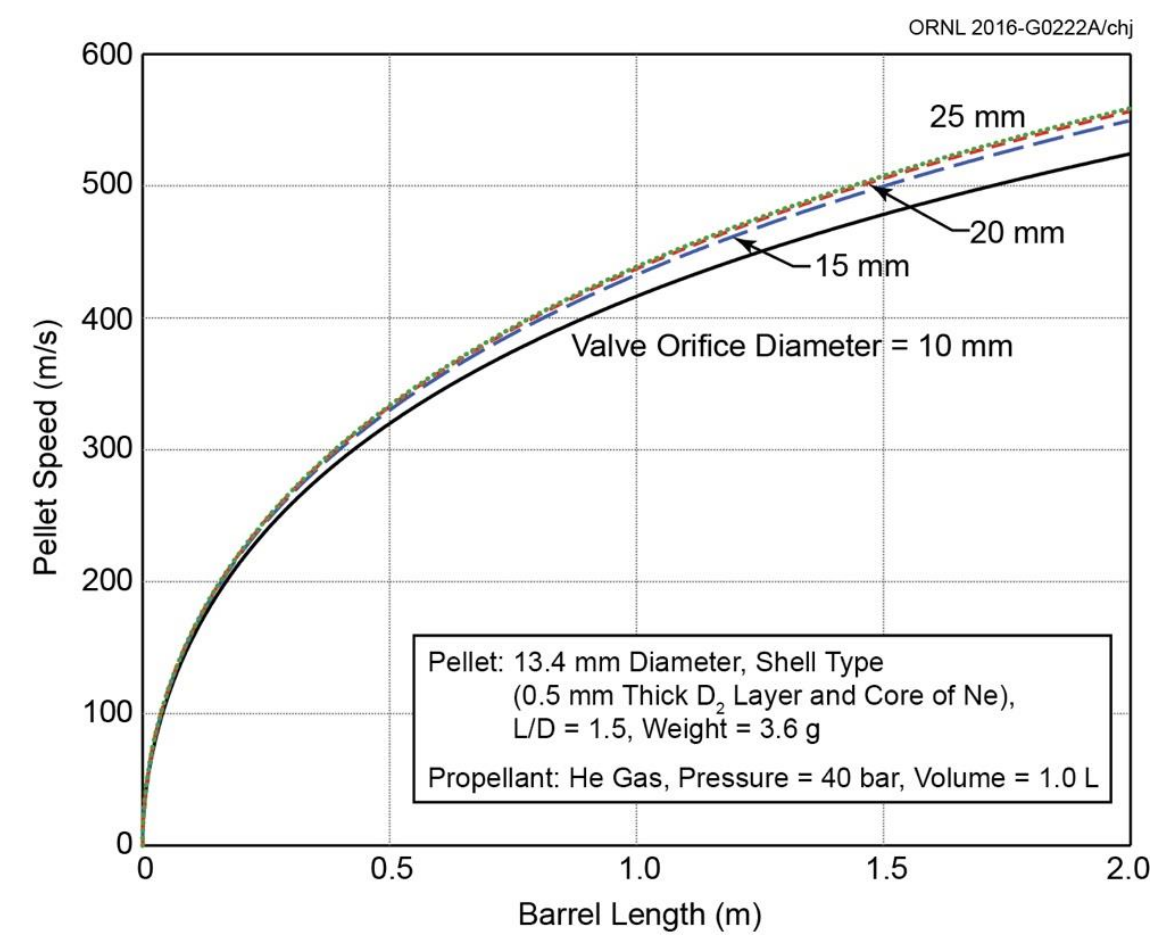

Fig. 9. Effects of propellant valve orifice size and barrel length on pellet speed for $13.4 \mathrm{~mm}$ shell pellets (smallest size planned for ITER). 


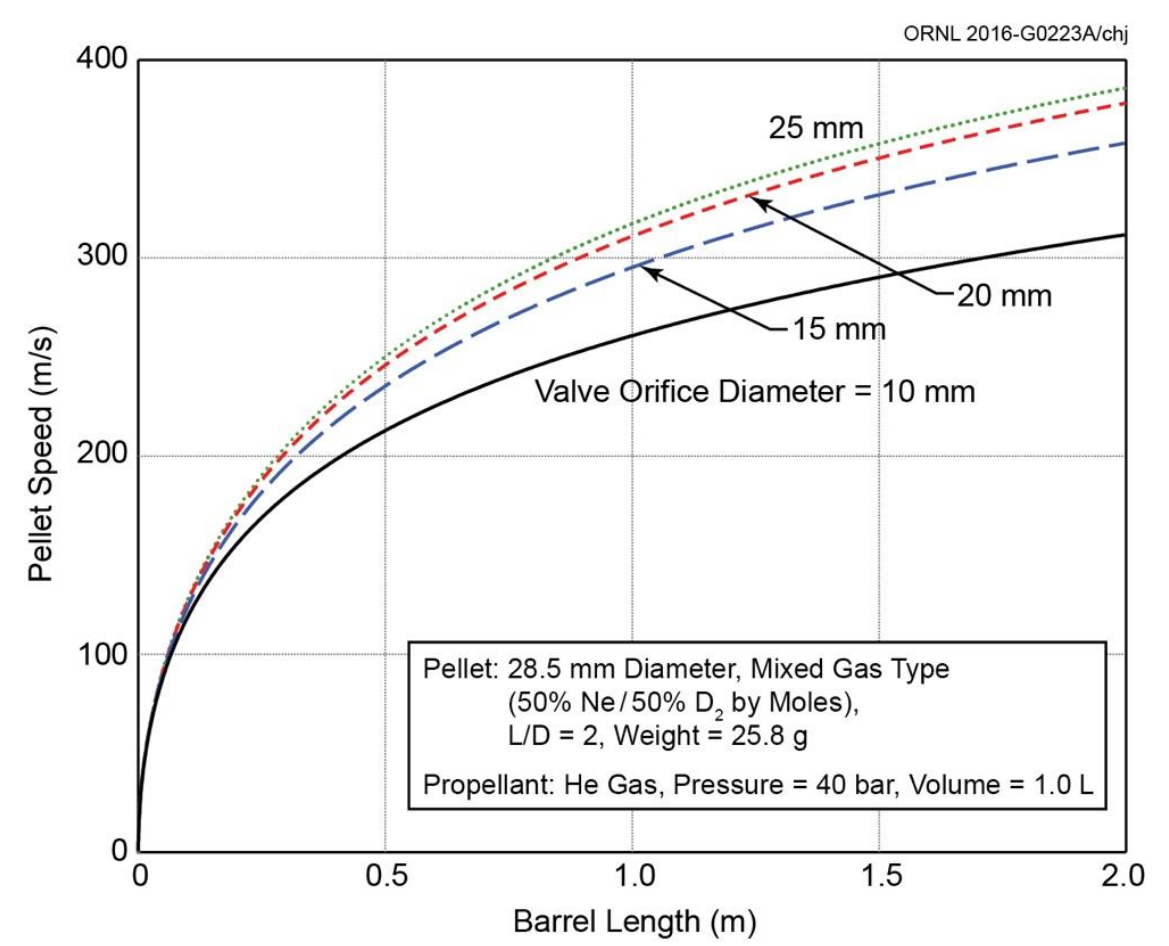

Fig. 10. Effects of propellant valve orifice size and barrel length on pellet speed for $28.5 \mathrm{~mm}$ pellets formed from mixed gas (largest size planned for ITER).

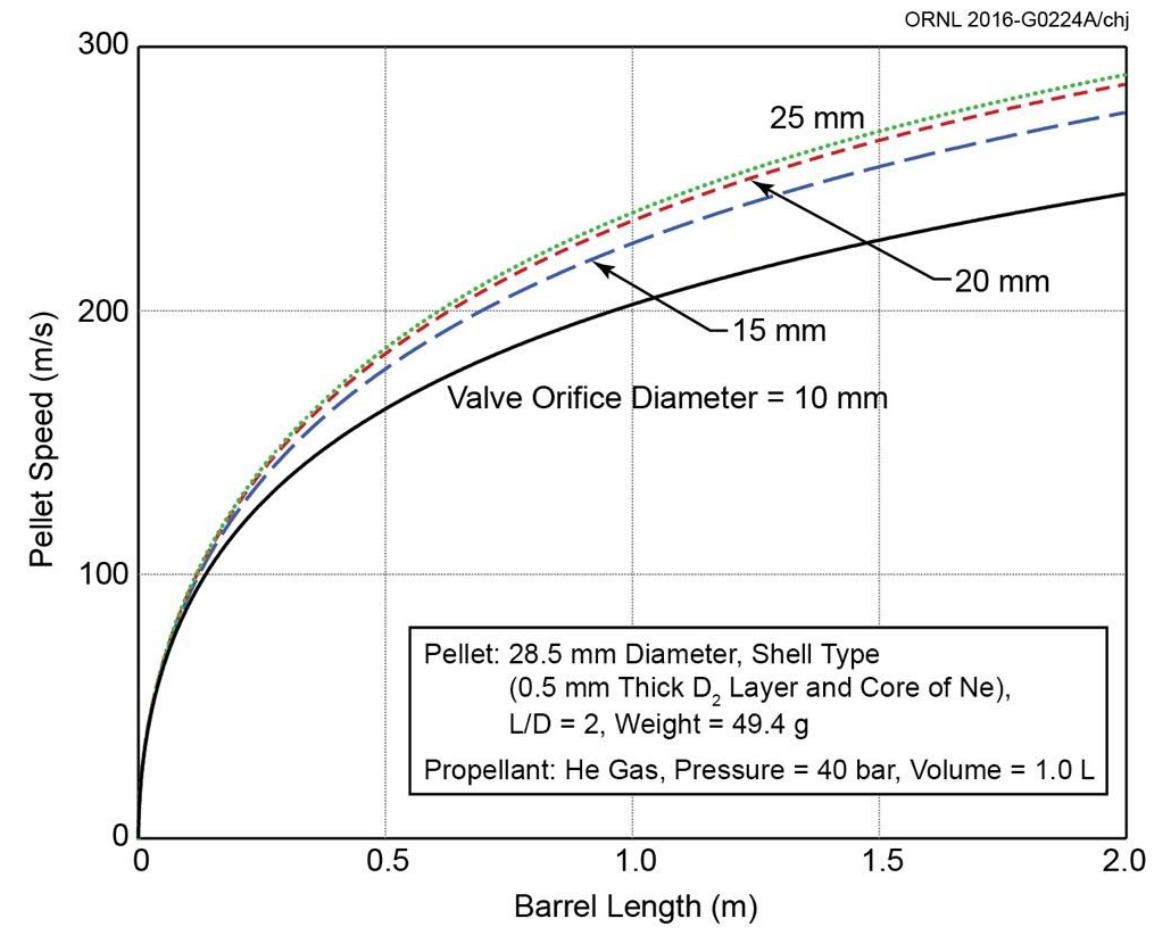

Fig. 11. Effects of propellant valve orifice size and barrel length on pellet speed for $28.5 \mathrm{~mm}$ shell pellets (largest size planned for ITER). 